DOI: 10.12957/demetra.2016.22334

\title{
Alimentação saudável, cuidado e gênero: percepções de homens e mulheres da Zona Noroeste de Santos-SP
}

\section{Healthy eating, health care and gender: perceptions of men and women from the Northwest region of Santos-SP}

Ana Flávia Martins Bernardes

Cristiane Gonçalves da Silva²

Maria Fernanda Petroli Frutuoso ${ }^{3}$

1 Universidade de São Paulo, Faculdade de Saúde Pública, Programa de Aprimoramento Profissional na Área de Nutrição em Saúde Pública. São Paulo-SP, Brasil.

${ }^{2}$ Universidade Federal de São Paulo, Departamento de Políticas Públicas e Saúde Coletiva, Instituto de Saúde e Sociedade. Santos-SP, Brasil.

${ }^{3}$ Universidade Federal de São Paulo, Departamento de Gestão e Cuidados em Saúde, Instituto de Saúde e Sociedade. Santos-SP, Brasil.

Correspondência / Correspondence Maria Fernanda Petroli Frutuoso

E-mail: fernanda.frutuoso@unifesp.br

\section{Resumo}

Este trabalho analisou a percepção de saúde e alimentação saudável, bem como as dinâmicas relacionadas à alimentação, em homens e mulheres de região de elevada vulnerabilidade. Trata-se de estudo qualitativo com entrevistas semiestruturadas com adultos residentes na área de abrangência de uma unidade de Saúde da Família. Os relatos sobre as concepções de saúde foram heterogêneos, e os entrevistados definiram saúde como ausência de doença, estresse e problemas na vida; hábitos e estilo de vida saudáveis. Em relação à alimentação saudável, a maioria das pessoas a associou ao consumo de frutas, legumes e verduras, enquanto a ingestão de gordura e açúcar foi considerada inadequada. Há poucas diferenças entre os relatos de homens e mulheres quanto à percepção sobre saúde e alimentação saudável; entretanto, quando se trata das dinâmicas alimentares, o homem aparece como protagonista apenas em celebrações, para ajudar a mulher ou quando sente vontade de cozinhar algo diferente. Em alguns casos, aos homens cabe ofertar recursos para aquisição dos alimentos, reforçando seu papel tradicional de provedor e a responsabilidade feminina de cuidar da alimentação da família. A vulnerabilidade do território não apareceu nos discursos como um fator que influencia a percepção de saúde e alimentação saudável. Diante da predominância de ações de saúde pautadas na redução de riscos e na normatização de corpos e estilos de vida, as diferenças entre homens e mulheres em relação à percepção sobre saúde e alimentação saudável colocam a categoria "gênero" como relevante no cuidado em saúde na contemporaneidade.

Palavras-chave: Saúde. Alimentação. Gênero. Cultura. Hábitos Alimentares. 


\section{Abstract}

This study examined the perception on health and healthy eating, as well as on food dynamics, of men and women from a economically vulnerable area. It is a qualitative study with semi-structured interviews with adults living in an area covered by a Family Health Unit. Reports of conceptions of health were heterogeneous, and respondents defined health as absence of disease and stress and as healthy habits and lifestyle. Most people associated the intake of fruits and vegetables with healthy eating while the intake of fat and sugar was considered inadequate. There are few differences between the discourses of men and women with regard to the perception of health and healthy eating. However, when it comes to food dynamics, men appear as protagonists only in celebrations with food, when they help their wives or when they wish to cook something different. In some cases, it is up to men to offer resources to food purchase, thus reinforcing the traditional role of males as providers and that of females as responsible for the family's feeding. The vulnerability of the territory did not appear in the discourse as a factor that influences their perception of health and healthy eating. Given the predominance of health initiatives based on risk reduction and standardization of bodies and lifestyles, the differences between men and women as regards their perception of health and healthy food turn gender into a relevant category in the field of health care nowadays.

Key words: Health. Feeding. Gender. Culture. Food Habits.

\section{Introdução}

Scliar ${ }^{1}$ identifica cinco momentos distintos ao longo da história da Saúde, a saber: mágico, empírico, moderno, autoritário, científico e social. Nos dois primeiros observavam-se, respectivamente, a doença relacionada aos elementos naturais/sobrenaturais e a dualidade entre corpo e mente. No período autoritário (século XVIII), o Estado absolutista exigia soluções para as pestilências da época, pautado na mudança de comportamento da população. O período moderno (século XIX), com o desenvolvimento das ciências e da pesquisa, caracteriza-se pela busca por um estado biológico normal. O período científico, sob o contexto da Revolução Industrial, voltouse para a contenção de epidemias e manutenção da saúde do operariado. O período social, na atualidade, caracteriza-se pelo foco na prevenção, na aproximação com a população e na presença de fatores subjetivos no processo de saúde-doença. 
Sob essa ótica, o conceito de saúde reflete fatores econômicos, políticos, culturais e sociais, bem como valores individuais, concepções científicas, religiosas e filosóficas. O processo histórico permeia, portanto, a interpretação de questões relacionadas ao processo de saúde-adoecimento-cuidado. ${ }^{1}$

Na atualidade, o risco tornou-se principal elemento para a elaboração de ações de cuidado em saúde e o reconhecimento e redução dos riscos se tornaram os principais objetivos das intervenções tanto na perspectiva da Saúde Pública como da clínica, incluindo a que se relaciona à alimentação. No entanto, os discursos atuais do cuidado em saúde, a busca por um corpo perfeito e um modo de vida saudável tomam parte da maioria das estratégias de normatização da vida humana. ${ }^{2}$

No olhar da Nutrição, o enfoque no risco epidemiológico leva prioritariamente a práticas profissionais pautadas na relação entre a ingestão de nutrientes e o aumento/diminuição da chance de adoecer e/ou morrer, restringindo as condutas à prescrição de alimentos, entendidos como saudáveis, reduzindo a complexidade da comida e do comer atual.,

Nesse contexto, a saúde, o corpo e a alimentação são entendidos como um objeto histórico e cultural, e desse modo passíveis de controle social. As percepções e os conceitos acerca do que é saúde, bem como do que é alimentação saudável, são mutantes e se reconstroem no cotidiano dos sujeitos e das coletividades. ${ }^{5}$ No contexto alimentar contemporâneo, a alimentação adequada é um dos hábitos de um modo de viver saudável que se define na busca pela moderação alimentar, seguindo uma proposição de alimentação saudável pautada, na maioria das vezes, na dicotomia entre permitido e proibido. ${ }^{6}$

Cultural e historicamente, mulheres e homens entendem e se relacionam de formas diferentes com a saúde e a alimentação, na medida em que o modo de conceber o masculino e o feminino implica determinados modelos de corpos, valores e comportamentos a serem seguidos pelas pessoas. ${ }^{5}$ No âmbito da saúde, uma diferença importante diz respeito à maneira como homens e mulheres buscam o cuidado em saúde. Sabe-se que mulheres procuram mais os serviços de atenção básica quando comparadas aos homens, e que estes tendem a procurar o serviço especializado de saúde, distanciando-se de ações de promoção de saúde e prevenção de doenças. ${ }^{7}$

Na perspectiva da alimentação, Contreras \& Gracia ${ }^{6}$ demonstraram diferenças encontradas no simples ato de cozinhar, ilustrando que, em várias culturas, as mulheres estão ligadas à alimentação no âmbito doméstico, enquanto nas sociedades em que cozinhar ganha um status diferenciado, o papel de cozinheiro chef é delegado ao homem.

Considerando os desafios profissionais diante do panorama de saúde e doença atuais, a construção social do gênero e do conceito de saúde/saudável e a soberania dos discursos científicos em detrimento ao conhecimento leigo, este artigo analisou a percepção de saúde e alimentação saudável, bem como as dinâmicas relacionadas à alimentação, na perspectiva de homens e mulheres, moradores de uma região de elevada vulnerabilidade de Santos, São Paulo. 


\section{Metodologia}

Foi realizado estudo de abordagem qualitativa. Segundo Minayo ${ }^{8}$ (p. 623):

Compreender é exercer a capacidade de colocar-se no lugar do outro, tendo em vista que, como seres humanos, temos condições de exercitar esse entendimento. Para compreender, é preciso levar em conta a singularidade do indivíduo, porque sua subjetividade é uma manifestacão do viver total. Mas também é preciso saber que a experiência e a vivência de uma pessoa ocorrem no âmbito da história coletiva e são contextualizadas e envolvidas pela cultura do grupo em que ela se insere.

A investigação foi realizada com moradores da área de abrangência de uma Unidade de Saúde da Família (USF) localizada na região Noroeste de Santos, São Paulo. Foram entrevistados sete homens e nove mulheres, com idade entre 20 e 40 anos, após assinatura do Termo de Consentimento Livre e Esclarecido. O trabalho foi aprovado pelo Comitê de Ética em Pesquisa da instituição (protocolo $\mathrm{n}^{\mathrm{0}}$ 733.141, de 30/07/2014).

A coleta de dados foi realizada por meio de entrevistas semiestruturadas, e as transcrições foram analisadas pela técnica de análise do conteúdo. ${ }^{9}$ As informações obtidas foram agrupadas em quatro categorias: 1) sobre o local e a população estudada; 2) sobre a construção do conceito de saúde e a busca de cuidado; 3) sobre a construção do conceito de alimentação saudável; 4) sobre a dinâmica da alimentação. As falas foram identificadas com M (mulher) e H (homem), considerando a categoria gênero como balizadora analítica dos discursos.

\section{Resultados e Discussão}

\section{Sobre o local e a população estudada}

A região recebeu um fluxo migratório muito intenso nas últimas décadas e conta com cerca de 100 mil habitantes. Apesar da existência de moradias de médio padrão, grande parte da comunidade vive em palafitas, sem acesso adequado a saneamento e infraestrutura básica, o que repercute nas condições de vida e saúde daqueles que ali residem. ${ }^{10}$

O território estudado possui estabelecimentos variados que comercializam alimentos, como bares, mercearias, sacolóes e feiras-livres; supermercados localizados, especificamente na avenida principal da região que liga os municípios de Santos e São Vicente, com destaque para as diversas redes de comércio atacadista.

A USF participante do estudo abrange quatro regiões bastante heterogêneas. A região 1, próxima geograficamente da USF, caracteriza-se por casas de alvenaria e sobrados bem estruturados; a 
região 2 é composta por um conjunto habitacional; a região 3, denominada "caminhos", apresenta extrema vulnerabilidade social, representada por residências simples e palafitas; e por fim, a região 4, mais distante da USF, possui casas de alvenaria em região de comércio intenso e muitos equipamentos de saúde, educação, lazer e cultura.

Foram feitas 16 entrevistas, sendo quatro pessoas de cada região, totalizando nove mulheres e sete homens, com idade entre 20 e 40 anos. Os entrevistados não apresentaram diferenças marcantes segundo as áreas de residência, sendo que catorze indivíduos contribuem para a renda familiar, sozinhos ou compartilhando com algum membro da família.

Das nove mulheres entrevistadas, sete compartilham a renda com os demais familiares; uma é responsável pela renda total da família e uma não participa da renda familiar. Em relação aos homens, dos sete entrevistados, três compartilham a renda, três são responsáveis pela renda total da família e um não participa da renda familiar.

No que diz respeito à preparação de alimentos, 15 dos entrevistados referem que uma mulher é responsável pela preparação de alimentos. Em relação à compra de alimentos, 11 pessoas contaram ser uma atividade exclusiva das mulheres enquanto três relataram ser uma atividade compartilhada com outros membros da família. Apenas um homem relatou ser o único responsável pela aquisição e preparação dos alimentos.

\section{Sobre a construção do conceito de saúde e a busca de cuidado}

Sobre as concepções de saúde, as respostas dos entrevistados se mostraram heterogêneas e apontam para três direções: ausência de doença, hábitos adequados e ausência de problemas como estresse.

O primeiro aspecto diz respeito à concepção de saúde relacionada á ausência de doença, relatado por quatro mulheres e um homem:

[...] não ter problema sério de saúde, controlar hipertensão, não ser diabético, controlar, fazer atividade física

e evitar os vícios. Graças a Deus não tenho nenhum. De vez em quando eu tomo uma cervejinha. É isso, se preparar para uma velhice que virá. (H8)

Viver melhor, não ter dor. Uma qualidade de vida, chegar até mais além, sem ficar acamado, isso jáé saúde. (M2)

O conceito de saúde compreendido como ausência de doenças é evidenciado em diversos estudos, com públicos distintos, como Dias, ${ }^{11}$ que estudou mães de crianças de até dois anos, residentes de um município de Minas Gerais, e Silva \& Bessa, ${ }^{12}$ em investigação com idosos de área periférica de Fortaleza-CE. 
Os depoimentos apontam também para uma concepção atravessada por hábitos como prática de atividade física e ausência de vícios, e o termo "controle" aparece como necessário para a manutenção da saúde.

[...] modo de vida. Como uma pessoa tá vivendo, o que ela tá comendo, educação. Acho que tudo isso tem a ver com saúde. (H7)

Saúde? Ter uma alimentação correta. Um esporte. (M11)

Separavich \& Canesqui ${ }^{7}$ apontam que, para os homens, os cuidados com a saúde e o corpo significam a prática de exercícios físicos, em primeiro lugar, seguida pela procura pelo médico em situações extremas.

Duas entrevistadas definiram "saúde" como a ausência de problemas, relacionados a aspectos subjetivos como estresse.

[...] uma pessoa bem. Sem nenhum tipo de problema. Sem estresse sem nada. (M10)

[...] não ter nenhuma 'dor de cabeça', sabe? Que nem meu caso tenho pressão alta, colesterol, tudo... (M16)

Nesse contexto, a dor de cabeça pode não ser entendida como uma dor física, mas como um estresse, aborrecimento. Para a entrevistada, o problema parece não ser a hipertensão, mas as causas dessa alteração ou, ainda, as dificuldades que o tratamento pode trazer para o cotidiano.

O sentido presente nesses discursos mostra a saúde como dependente do contexto social do indivíduo. Segundo Minayo, ${ }^{13}$ o "nervoso da vida" foi o principal causador de problemas de saúde entre homens e mulheres adultos, moradores de favelas do Rio de Janeiro, sendo responsável pelo surgimento de outros males e associado a uma série de sintomas e muitas queixas. A autora relaciona esse problema a um "sentimento de opressão e de dificuldade insana para levar adiante o projeto familiar, todo ele construído sobre a sobrevivência do dia a dia” (p. 368). ${ }^{13}$

Uma das entrevistadas acredita que as condições climáticas interferem diretamente em sua saúde: "pra minha saúde é o tempo. Se tiver muito calor acaba comigo. Um tempo mais fresco pra mim é muito perfeito" (M10). Fatores climáticos influenciando a saúde também foram apontados por Minayo, ${ }^{13}$ na medida em que fatores da natureza foram relacionados ao nervosismo; dores no corpo; recrudescimento de males crônicos, gripes e resfriados.

Ao serem questionados sobre o que acreditam fazer bem à saúde, os entrevistados relataram hábitos cotidianos: "três coisas na minha opinião: dormir bem; me alimentar bem e fazer atividade física” (H8). Uma parte importante dos entrevistados (11 indivíduos) afirmou que o que faz bem 
para sua saúde é a alimentação saudável ou uma boa alimentação associada à prática de exercícios: "alimentação saudável, exercício físico, e bastante liquido também. Pra não deixar cair" (H3). E uma das mulheres associa a saúde a práticas de higiene e saneamento básico: "exercício fisco ter cuidado com a alimentação, lavar a mão direito, saneamento básico e essas coisas" (M1).

Os relatos dos entrevistados parecem concordar com um discurso de polaridade, conforme discutido por Costa \& Bernardes, ${ }^{14}$ que pontuam que ao classificar saúde como ausência de, criase uma complexa situação de bipolaridade, em que a doença e a saúde estão em uma relação de oposição, sendo que a oposição implica afirmar saúde pela negação da doença.

Ao serem questionados sobre atitudes que tomam quando enfrentam algum problema de saúde, a maioria dos entrevistados respondeu que é procurar o médico ou um equipamento de saúde. Foi recorrente a automedicação como estratégia de cuidado, especialmente em casos de sintomas já conhecidos e vivenciados anteriormente.

[...] vou ao médico. Tomo remédio. Se eu souber o que que é, já tiver o medicamento em casa, já ter passado por essa situação outra vez e tiver o medicamento em casa ai eu me auto medico. (M1)

Minayo $^{13}$ discute que o padrão biomédico é o modelo dominante de "cuidado" e que tem mecanismos de aproximação, de propaganda e de imposição que o legitimam. Segundo Mandú \& Silva, ${ }^{15}$ sujeitos optam pelos fármacos como recursos para a resolução de problemas de saúde, influenciados por propagandas e estímulos resultantes das práticas biomédicas dos serviços de saúde, de onde dificilmente se sai sem uma receita médica.

A dificuldade de acesso aos serviços e de cuidar dos problemas de saúde foi apontada por dois entrevistados, incluindo a dificuldade por não conseguir acompanhamento tanto no serviço público de saúde como no privado:

[...] eu tenho convênio, mas é difícil ir ao médico! Você vai na policlínica e não consegue nada. Aí o convênio agora subiu lá em cima, eu tive que fazer, isso é absurdo. Ainda nem fui nesse convênio novo. Quando não dá a gente vai comprar um remédio na farmácia e vai empurrando com a barriga. (M15)

Por outro lado, um dos entrevistados coloca explicitamente que os padrões de gênero estão relacionados ao modo como se lida com saúde, ou seja, que os homens procuram menos os serviços de saúde.

[...] eu não procuro saber de nada, de fazer nenhuma prevenção, nem nada entendeu? Coisa de homem, né? (H11) 
Braz $^{16}$ e Gomes et al. ${ }^{17}$ concluíram que a construção da subjetividade masculina e o entendimento do que é ser homem dificultam a adoção de práticas de autocuidado, pois à medida que o homem é visto como viril, invulnerável e forte, a procura pelo serviço de saúde, na perspectiva a prevenção de doenças, poderia associá-lo a fraqueza, medo e insegurança. Poderia, portanto, aproximá-lo das representações do universo feminino, o que implicaria possivelmente desconfianças acerca dessa masculinidade socialmente instituída. Isso o coloca em uma posição de vulnerabilidade física e psíquica, já que não pode admitir fragilidade ou adoecimento, o que o torna susceptível aos riscos de agravamento de uma doença que poderia ser evitada.

\section{Sobre a construção do conceito de alimentação saudável}

De todos os entrevistados, 13 definiram "alimentação saudável” com o comer frutas, verduras e legumes. Foram também feitas associações entre comida saudável e a ausência de gorduras e óleo, e a presença de carnes e peixes.

[...] frutas, verduras, sem muito óleo, sem muita gordura... isso sim é uma alimentação saudável. (H3)

[...] verdura! Acho que verdura é uma alimentação saudável, salada e acho que carne é saudável e peixe é saudável. (M4)

Em muitas respostas notou-se que o consumo de gordura e açúcar é considerado aversivo, que definitivamente não é compatível com uma alimentação saudável: "[...] de jeito nenhum é saudável gordura, muito doce" (M4).

Uma das entrevistadas apontou que alimentação saudável significa "ter todos os tipos de nutrientes que o corpo precisa" (M1). Nesse sentido, Sant’Anna ${ }^{18}$ trata da nova tendência atual da produção de "alicamentos", ou seja, alimentos que são consumidos visando à biodisponibilidade de nutrientes que tragam algum benefício para o organismo. Segundo Freitas \& Santos, ${ }^{19}$ o sentido da saúde e do comer saudável, em um contexto de subjetividades, é permeado pelo discurso biomédico, que leva o indivíduo a reproduzir o discurso normativo (frutas e legumes, por exemplo) descolado de história de pessoa, família e comunidade.

Mesmo não sendo possível notar diferenças no conteúdo das entrevistas entre mulheres e homens, quando o tema era a alimentação saudável, uma das entrevistadas destacou-se, na medida em que classificou comer bem como comer o que quiser, associando o hábito de comer verdura à "frescura":

Ai menina... comer bem, o que quiser! Com uma cerveja. Nada dessas coisas de gordurinha, essas coisinhas de fresco não. Comer bem e pronto. Adoro comer uma besteira! Adoro! Ficar nessa rotina de verdurinha, isso é coisa pra fresco. Uma feijoada é comer bem; e tomar uma cerveja. (M9) 
Nesse contexto, insere-se a dualidade existente entre alimentação e nutrição, apresentada por Villagelim, ${ }^{4}$ quando relaciona a nutrição ao componente biológico e a alimentação ao social, cultural e sentidos. Para a entrevistada, em um contexto singular, sua vivência alimentar e sua história de vida permitem construir outro significado para o comer bem, distante e resistente ao discurso hegemônico. O sentido da alimentação é fruto da experiência em um mundo social e a feijoada, referida pela participante, é um capital simbólico, identidade do brasileiro e da região estudada. Há sentidos e símbolos que anunciam definições a partir de como o sujeito se insere no mundo e como resistência a um discurso hegemônico sobre padrões de alimentação e de corpos que associam a ideia de saudável a determinado padrão estético, especialmente para mulheres.

Outra questão apontada é a relação entre alimentação saudável e "alimentos permitidos", decorrentes de proibições/restrições, como tratamento de alguma patologia: "comer só coisa que pode. Tô comendo só uma colher de arroz, de feijão, não tô comendo gordura, não tô comendo pão por causa da pré-diabetes" (M13), o que indica que a alimentação ganhou um novo significado a partir da necessidade de restrição em decorrência de alguma doença, como a diabetes.

Quando questionados se consideram a própria alimentação saudável, a maioria dos participantes afirmou positivamente, com exceção de dois entrevistados, que relataram problemas alimentares relacionados à falta de tempo para comer no horário e ao consumo de determinados tipos de alimentos, de elevado teor calórico:

Eu acho que não. Até porque eu como sempre fora de hora. Geralmente é bom sempre comer no horário. A gente que fica sempre na correria não tem muito tempo pra isso. (H11)

Nenhum pouco. Porque eu como ovo, eu como muita fritura, muita massa e muito refrigerante. (M10)

Azevedo ${ }^{3}$ discute que a alimentação passou por um processo de racionalização que lhe confere um caráter dietoterápico, com enorme influência na compreensão da população sobre alimentação saudável, concebida como contendo alimentos com pouca gordura, sal e açúcar; rica em frutas, verduras e legumes. $\mathrm{O}$ aspecto restritivo dessa perspectiva segue a ideia de alimentação saudável em uma vertente "energético-quantitativa".

Um dos entrevistados relatou que considera a alimentação parcialmente saudável, uma vez que não consegue perder peso seguindo a rotina alimentar que possui: "mais ou menos... Por mais que eu diminua, eu não consigo perder peso, mantenho sempre o mesmo peso" (H2). Nesse contexto, Witt \& Schneider ${ }^{20}$ pontuam que a preocupação com a beleza é o centro das atenções de toda humanidade, e o cuidado estético tem se difundido a cada dia. Esse processo tem grande impacto sobre a autoimagem, principalmente entre as mulheres, que se sentem obrigadas a ter um corpo magro. 
Santos et al.,. ${ }^{21}$ em artigo de reflexão baseado em revisão bibliográfica, afirmam que a insatisfação com o corpo é produzida sistematicamente, levando as mulheres, especialmente as de baixo nível socioeconômico, a sentirem que estão sempre longe do padrão valorizado - e inalcançável - como ideal.

Scagliusi et al., ${ }^{22}$ em estudo quantitativo sobre a insatisfação corporal de mães residentes no município de Santos, incluindo a região do presente estudo, evidenciaram que a maioria das mulheres estava insatisfeita com seus tamanhos corporais, sendo frequente a prática de dietas restritivas e comportamentos de risco para transtornos alimentares. Esses achados reforçam que a sociedade contemporânea cultua a magreza como uma situação ideal de aceitação social entre as mulheres e rejeita a obesidade, associando a gordura à doença e à falta de controle sobre o corpo. A cobrança exagerada em relação ao peso e às medidas, especialmente para as mulheres, gera insatisfações pessoais e distorções da imagem corporal.

Teo, ${ }^{23}$ ao estudar o discurso e a construção do senso comum sobre alimentação em revistas femininas, percebeu uma exaltação da boa forma, numa relação ambígua entre beleza e saúde, somada a práticas alimentares por vezes equivocadas e atestadas por um enunciado classificado como pretensamente científico e por um discurso sócio-estético que tem como base o padrão de beleza contemporâneo, resultante de um momento sócio-histórico de valorização das tecnologias da estética e de apologia ao individualismo e à competitividade.

Historicamente, a preocupação com o corpo e a beleza se restringiu às mulheres. Os homens, a partir do século XXI, começaram a se preocupar com o corpo no sentido de serem fortes, potentes e viris, a partir de uma musculatura definida, o que desloca a busca pela construção do corpo perfeito de uma preocupação restritamente feminina. ${ }^{24}$

A garantia da segurança alimentar e nutricional, entendida como o direito de todos ao acesso regular a alimentos de qualidade e em quantidades suficientes, sem que isso comprometa o acesso às demais necessidades essenciais, depende de ações articuladas que incluem, além do preço praticado pelo mercado, a disponibilidade, a produção, a distribuição e o acesso físico aos alimentos. ${ }^{25} \mathrm{Os}$ entrevistados, moradores de região de elevada vulnerabilidade, não atribuíram dificuldades financeiras para uma alimentação saudável, tampouco dificuldade de acesso físico para a compra de gêneros alimentícios, que poderia ser dificultado pelas ruas e becos estreitos, característicos das áreas de palafitas da região 3. Os limitadores da alimentação saudável relacionaram-se ao pouco tempo para alimentação, à presença de doenças que demandaram restrições alimentares e às escolhas por alimentos reconhecidos como pouco saudáveis pelos entrevistados cujas razões não puderam ser exploradas neste estudo.

Bertran, ${ }^{26}$ em estudo com mulheres mexicanas de três estratos socioeconômicos, constatou que a alimentação saudável é permeada por questões complexas e contraditórias, que incluem a ampla diversidade de alimentos disponíveis, as consequências adversas decorrentes dos excessos 
alimentares, a busca pelo prazer e corpo perfeito, independentemente do estrato social. No presente estudo, essas questões predominaram nos discursos em detrimento da questão da vulnerabilidade social e de saúde presente no território.

\section{Sobre a dinâmica da alimentação}

Em quase todas as entrevistas foi possível identificar que, no contexto familiar, a figura feminina representada no papel de esposa, mãe, irmã e filha, é responsável pela alimentação de todos os moradores da casa. Esta responsabilidade é tanto pelo preparo quanto pela compra de alimentos consumidos pela família e, em alguns casos, há a divisão parcial das outras atividades não realizadas na cozinha, reportada por três homens e uma mulher:

[...] moro com meus pais, três filhos e meu marido... A gente [eu e minha mãe] compra de tudo, vai no mercado, faz a listinha e traz tudo. A única coisa que eles [pai e marido] fazem é ir buscar a gente no mercado. (M4)

Colocando em análise a relação entre alimentação e gênero, sabe-se que, histórica e culturalmente, cabe às mulheres a preparação dos alimentos e a limpeza dos utensílios/cozinha, como responsabilidade "natura" e como parte do cuidado dos membros do domícilio. ${ }^{6}$ Em alguns casos, aos homens cabe o papel de ofertar recursos para a compra de gêneros alimentícios, sejam financeiros ou relacionados ao transporte: "minha mãe. Ela quem faz. Eu pago, mas ela quem faz" (H8).

O homem só aparece, no contexto da cozinha, como cozinheiro da família em eventualidades para ajudar a esposa ou quando sente vontade de cozinhar. Não se trata de corresponsabilização, mas sim de uma participação esporádica.

\section{[...] porque dificilmente eu estou em casa, quando eu estou em casa eu faço pra poder ajudar ela. (H11)}

Quando questionados sobre o porquê de as mulheres serem responsáveis pela alimentação de toda a família, os discursos apontam justificativas como "as mulheres gostam de cozinhar" ou "sabem cozinhar e não trabalham fora de casa", o que nos permite identificar certa essencialização das atribuições domésticas como constitutivo da vida e do universo de mulheres.

Apesar de observarmos importantes conquistas políticas na direção da igualdade de gênero, no ambiente doméstico as divisões de tarefas parecem não ter sofrido muita alteração. Neste estudo, as mulheres são, em geral, responsáveis por administrar as demandas alimentares da família, como compras e organização do cardápio. Outros autores mostram que as mulheres costumam 
ser reconhecidas como cuidadoras da saúde da família por intermédio da alimentação. ${ }^{27,28}$ Para

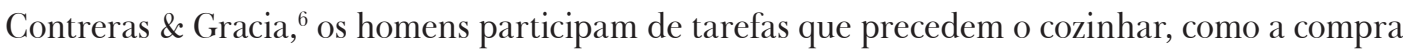
de gêneros alimentícios e também da preparação de alguns pratos, como por exemplo, as carnes assadas. Assim, a conveniência de produtos alimentícios/refeições prontos, a tecnologia dos equipamentos domésticos, a oferta de alimentação fora de casa e a entrada da mulher no mercado de trabalho não tiraram desse grupo o papel de protagonista na preparação dos alimentos.

Segundo Casotti, ${ }^{29}$ diferentemente de outros espaços da casa, que têm identidades ambíguas e podem ser dominados por outros membros da família, a cozinha tem uma identidade feminina. É definida, na maioria das vezes, como um espaço feminino no qual mesmo as mulheres que trabalham fora em tempo integral e não gostam de cozinhar relatam algum tipo de relação com o preparo da comida.

No ambiente familiar, poucos homens cozinham e a participação deste grupo na preparação da comida e em outras atividades domésticas, como limpar a casa, lavar louças e lavar roupas, é pequena. Quando fazem algumas dessas atividades, seu trabalho é considerado uma "ajuda" à mulher. Isso acontece quando a mulher não pode realizar esta função, como por exemplo, quando ela fica doente. ${ }^{27}$

De acordo com Romanelli, ${ }^{30}$ existe uma tendência para a dessexualização ${ }^{a}$ do ato de cozinhar. E, como resultado deste processo, é possível identificar uma reificação do lugar de privilégio masculino, na medida em que o papel do homem na cozinha tem visibilidade na mídia e está nitidamente associado ao lazer, a uma profissão de destaque, a atividades agradáveis e repousantes de preparação de pratos sofisticados e requintados, em um segmento social representado por artistas, esportistas e executivos, e não a homens comuns e em contraponto ao ambiente formal e estressante do trabalho. Entre os entrevistados, isso ocorre mesmo considerando a diferença de contexto, já que a adesão dos homens na preparação de alimentos ocorre apenas em ocasiões especiais, permanecendo o preparo cotidiano de alimentos uma tarefa feminina.

\section{Considerações finais}

Sobre o conceito de saúde, a população estudada referiu que ter saúde significa ausência de doença; ter hábitos e estilo de vida saudáveis; não ter estresse e problemas. Ao considerar a alimentação saudável, os entrevistados a definem como o consumo de frutas, legumes e verduras, além do controle da ingestão de gorduras. A responsabilidade de cuidar da alimentação da família,

a Cabe aqui destacar que sexo é uma categoria diversa de gênero. A ideia de gênero desnaturaliza o masculino e o feminino, que definem e se restringem à dimensão biológica. Esta nota é necessária para que possamos indicar que, no nosso entendimento, a palavra mais adequada seria "desgenerificação" do ato de cozinhar e não "dessexualização". 
seja comprando, escolhendo ou preparando os alimentos, na maioria dos casos, é feminina. Em relação à percepção sobre saúde e alimentação saudável, há poucas diferenças entre homens e mulheres. Os resultados revelam complexidades maiores para apreensão do gênero, quando se trata de alimentação saudável e manejo da alimentação, apontando para a riqueza do universo a ser ainda mais explorado.

Portanto, é preciso investir na interlocução entre alimentação e gênero enquanto categoria analítica, porque é estratégica para que se possa compreender o sentido da alimentação na vida das pessoas. É preciso também investir no estudo sobre os contextos e as condições socioeconômicas dos sujeitos e perceber como operam as pedagogias culturais de gênero na alimentação dentro e fora de casa. Cada vez mais, é preciso compreender questões da feminilidade e masculinidade relacionadas à alimentação e ao comer.

\section{Referências}

1. Scliar M. História do conceito de saúde. PHYSIS: Rev. Saúde Coletiva 2007; 17(1):29-41.

2. Czeresnia D. Ciência, técnica e cultura: o conceito de risco epidemiológico. In: Czeresnia D. Categoria vida: reflexões para uma nova biologia. Rio de Janeiro: Fiocruz; 2012. p. 9-26.

3. Azevedo E. Reflexões sobre riscos e o papel da ciência na construção do conceito de alimentação saudável. Rev. Nutrição 2008; 21(6):717-723.

4. Villagelim ASB, Prado SD, Freitas RF, Carvalho MCVS, Cruz CO, Klotz J, et al. A vida não pode ser feita só de sonhos: reflexões sobre publicidade e alimentação saudável. Ciênc. Saúde Coletiva 2012; 17(3):681-686.

5. Melo CM, Oliveira DR. O uso de inibidores de apetite por mulheres: um olhar a partir da perspectiva de gênero. Ciênc. Saúde Coletiva 2011; 16(5):2523-2532.

6. Contreras J, Gracia M. Alimentação, sociedade e distinção social. In: Contreras J, Gracia M. Alimentação, sociedade e cultura. Rio de Janeiro: Editora Fiocruz; 2011. p. 211-87.

7. Separavich MA, Canesqui AM. Saúde do homem e masculinidades na Política Nacional de Atenção Integral à Saúde do Homem: uma revisão bibliográfica. Saúde e Sociedade 2013; 22(2):415-428.

8. Minayo MCS. Análise qualitativa: teoria, passos e fidedignidade. Ciênc. Saúde Coletiva 2012; 17(3):621-626.

9. Minayo MCS. O desafio do conhecimento: pesquisa qualitativa em saúde. $14^{a}$ ed. São Paulo: Hucitec; 2014. 407 p.

10. Mendes R, Capozzolo AA, Lima Junior RT, Andrade V, Souza BM, Silva MGPS, et al. Tessituras e participação: extensão na região noroeste de Santos. Rev. Ciênc. Ext. 2014; 10(1):7-16. 
11. Dias G, Franceschini SCC, Reis JR, Reis RS, Siqueira-Batista R, Cotta RMM. A vida nos olhos, o coração nas mãos: concepções e representações femininas do processo saúde-doença. Hist. Ciênc. Saúde-Manguinhos 2007; 14(3):779-800.

12. Silva MJ, Bessa MEP. Conceitos de saúde e doença segundo a óptica dos idosos de baixa renda. Ciênc. Enfermagem 2008; 14(1):23-31.

13. Minayo MCS. Saúde-doença: uma concepção popular da etiologia. Cad. Saúde Pública 1988; 4(4):36381.

14. Costa ML, Bernardes AG. Produção de saúde como afirmação de vida. Saúde e Sociedade 2012; 21(4):822-35.

15. Mandú ENT, Silva GB. Recursos e estratégias em saúde: saberes e práticas de mulheres dos segmentos populares. Rev. Latino-Americana de Enfermagem 2000; 8(4):15-21.

16. Braz M. A construção da subjetividade masculina e seu impacto sobre a saúde do homem: reflexão bioética sobre justiça distributiva. Ciênc. Saúde Coletiva 2005; 10(1):97-104.

17. Gomes R, Nascimento EF, Araújo FC. Porque os homens buscam menos os serviços de saúde do que as mulheres? As explicações de homens com baixa escolaridade e homens com ensino superior. Cad. Saúde Pública 2007; 23(3):565-574.

18. Sant'Anna DB. Dietética e conhecimento de si. In: Rago M; Veiga-Neto A, organizadores. Para uma vida não-fascista. Belo Horizonte: Autêntica; 2009. p. 83-94.

19. Freitas MCS, Santos LAS. Sobre a fenomenologia do comer saudável no mundo da vida: breve ensaio. In: Freitas MCS, Silva DO, organizadores. Narrativas sobre o comer no mundo da vida. Salvador: EDUFBA; 2014. p. 33-39.

20. Witt JSGZ, Schneider AP. Nutrição estética: valorização do corpo e da beleza através do cuidado nutricional. Ciênc. Saúde Coletiva 2011; 16(9):3909-3916.

21. Santos MA, Garcia RWD, Santos ML. A sujeição aos padrões corporais culturalmente construídos em mulheres de baixa renda. Demetra 2015; 10(4):761-774.

22. Scagliusi FB, Pereira PR, Stelmo IC, Unsain RF, Martins PA, Sato PM. Insatisfação corporal, prática de dietas e comportamentos de risco para transtornos alimentares em mães residentes em Santos. J. Bras. Psiquiatria 2012; 61(3):159-67.

23. Teo CRPA. Discursos e a construção do senso comum sobre alimentação a partir de uma revista feminina. Saúde e Sociedade 2010; 19(2):333-346.

24. Santos ARM, Silva EAPC, Moura PV, Dabbicco P, Silva PPC, Freitas CMSM. A busca pela beleza corporal na feminilidade e masculinidade. Rev. Bras. Ciênc. Movimento 2013; 21(2):135-142.

25. Rocha C, Burlandy I, Magalhães R. Segurança alimentar e nutricional: perspectivas e desafios para as políticas públicas. Rio de Janeiro: Editora Fiocruz; 2013. 225p.

26. Bertran M. Alimentación e incertidumbre en la vida cotidiana en la ciudad de México: narrativas sobre la alimentación saludable. In: Freitas MCS, Silva DO, organizadores. Narrativas sobre o comer no mundo da vida. Salvador: EDUFBA; 2014. p. 33-39. 
27. Assunção VK. Comida de mãe: Comida de mãe: notas sobre alimentação, família e gênero. Cad. Espaço Feminino 2008; 19(01):233-253.

28. Fonseca AB, Souza TSN, Frozi DS, Pereira RA. Modernidade alimentar e consumo de alimentos: contribuições sócio antropológicas para a pesquisa em nutrição. Ciênc. Saúde Coletiva 2011; 16(9):3853-3862.

29. Casotti L. À mesa com a família: um estudo do comportamento do consumidor de alimentos. Rio de Janeiro: Mauad; 2002. 157 p.

30. Romanelli G. O significado da alimentação na família: uma visão antropológica. Medicina 2006; 39(3):333-9.

Recebido: 05/4/2016

Revisado: 30/7/2016

Aceito: 16/8/2016 
